\section{Body mass index percentiles in adolescents of the city of São Paulo, Brazil, and their comparison with international parameters}

\author{
Percentis do índice de massa corporal de adolescentes na cidade de \\ São Paulo, Brasil, e sua comparação com parâmetros internacionais
}

Maria Aparecida Zanetti Passos', Isa de Pádua Cintra', Lúcia Maria Branco², Helymar da Costa Machado ${ }^{3}$, Mauro Fisberg'

\begin{abstract}
Objective: To describe the percentile distribution of body mass index (BMI) in school adolescents, by gender and age, comparing them with international parameters. Subjects and methodls: The study included 8,020 adolescents aged 10-15 years from 43 schools in the city of São Paulo, southeastern Brazil. BMI values of the study sample were distributed in percentiles and compared to international parameters (CDC, Must and cols. and Cole and cols.). Results: Both male and female adolescents aged 10 to 14 years showed BMI cut-offs over the international parameters, especially in the P50-P85 percentile range. At the age of 15 , the observed values were very similar to reference data; however, BMI values in the 95th percentile were much higher than international parameters. Conclusions: The study results show how important it is to use adequate BMI values for Brazilian adolescents aged 10-15 since international parameters may not reflect the actual nutritional status of this group. Arq Bras Endocrinol Metab. 2010;54(3):295-302
\end{abstract}

\section{Keywords}

Body mass index; obesity; adolescent; anthropometric

\section{RESUMO}

Objetivo: Distribuição do índice de massa corporal (IMC) em percentis dos adolescentes escolares, divididos por sexo e idade, comparando-os com os parâmetros internacionais. Sujeitos e métodos: Participaram do estudo 8.020 adolescentes de 10 a 15 anos de 43 escolas da cidade de São Paulo. Os valores do IMC dessa população foram distribuídos em percentis e comparados com os parâmetros internacionais (CDC, Must e Cole). Resultados: Os adolescentes dos 10 aos 14 anos de idade, do sexo masculino e feminino, apresentaram pontos de corte do IMC acima dos internacionais, especialmente no intervalo P50-85. Aos 15 anos de idade, os valores observados foram muito semelhantes, no entanto, o IMC no valor do percentil 95 foi muito mais elevado do que os parâmetros internacionais. Conclusões: Os resultados deste estudo demonstram a importância de utilizar valores adequados para adolescentes brasileiros de 10 a 15 anos, uma vez que os parâmetros internacionais podem não refletir a real condição do estado nutricional dessa população. Arq Bras Endocrinol Metab. 2010;54(3):295-302

\section{Descritores}

Índice de massa corporal; obesidade; adolescente; antropometria
${ }^{1}$ Centro de Atendimento e Apoio ao Adolescente, Departamento de Pediatria, Universidade Federal de São Paulo (Unifesp), São Paulo, SP, Brasil ${ }^{2}$ Escola Técnica Estadual (ETEC) Getúlio Vargas. Centro Paula Souza, São Paulo, SP, Brasil ${ }^{3}$ Divisão de Estatística, Universidade Estadual de Campinas (Unicamp), Campinas, SP, Brasil

\section{INTRODUCTION}

$\mathrm{T}$ he use of anthropometric measures in the nutritional evaluation of individuals and populations has become the most practical and the least costly approach.
It can be used for clinical purposes, screening and even for monitoring tendencies ( 1 ).

Researchers have reported an increase in the prevalence of overweight and obesity in recent decades. Body mass 
index (BMI), largely used among adults, has been increasingly used to describe and classify the nutritional state of children and adolescents. In addition to being reliable, practical to obtain and easy to understand, BMI shows good correlation with the amount of body fat $(2,3)$.

Based on the recommendation for the use of BMI as a criterion for screening excess body fat in obesity among children and adolescents $(4,5)$, and in studies that show exponential increase of obesity both in developed and developing countries $(6,7)$, the discussion regarding its use to evaluate the nutritional state of the young population has been focused on the choice of the most adequate curve and the definition of critical values for nutritional classification of obesity (1).

The lack of consensus in literature on the criteria to define obesity in children and adolescents points to the need for researchers to establish specific cut-offs for each population. Therefore, the purpose of the present study was to describe the percentile distribution of BMI values among students aged 10 to 15 years in the city of São Paulo, Brazil, comparing them to international parameters and to evaluate these students as for overweight and obesity by age and gender.

\section{SUBJECTS AND METHODS}

\section{School sampling}

For school selection, the 2002 school census including a list of all the schools in the city of São Paulo was obtained from the regional school jurisdictions. The city was then divided into four areas of study (northern, midwestern, eastern, and southern areas) so that differentiated social groups would be included in the sample.

The proportional sample was stratified according to school inclusion in the socio-geographic areas and their administrative category (public or private). The total number of schools was determined based on the proportion in each area so that the area with the largest number of schools would have the highest number of students included in the study. A proportionality ratio was established between public and private schools in each area; i.e., if there were 10 public and 5 private schools, the ratio would be $2: 1$, but this proportionality was not the same for all the areas studied. The schools that met the following study inclusion criteria were then selected: minimum of 200 students (50 students per grade) enrolled from 5 th to 8 th grade; easily accessible facility; and day and/or evening classes. Using stratified, proportional-to-size sampling procedures, schools were drawn to be included in the sample.

The schools were contacted and meetings were scheduled. These meetings were opportunities for explaining the study objectives and showing all materials that would be used in the study. During these expositions the importance of evaluating adolescents for early detection of any nutritional deviations was stressed.

When a school refused to participate it was replaced by another one from the same district, previously numbered and randomly drawn.

All schools for which the principals signed a letter of authorization participated in the study. After their agreement to participate in the study, a meeting was scheduled with the school teachers to explain to them the study objectives so they could help us approach the adolescents and collect data. A great effort was made not to disrupt the school routine during data collection.

A representative sample of the city of São Paulo was studied including 43 schools ( 32 public and 11 private) from the northern $(17 \%)$, midwestern $(17 \%)$, eastern (37\%), and southern $(29 \%)$ areas of the city; most public schools are located in the eastern area of the city (11; $34.4 \%)$ and a larger number of private schools is seen in the southern area $(6 ; 54.5 \%)$ of the city.

\section{Study population}

The present study is part of a large project denominated "Life Habits and Nutritional Status of Adolescents Attending Public and Private Schools in the City of São Paulo". No formula was used to estimate the sample size as we opted for a probabilistic approach and all adolescents attending the schools that were drawn and which met the inclusion criteria were selected. However, data was only collected from those students who signed an informed consent. The sample included 8,020 adolescents aged 10 years old and one day to 15 years old and 29 days, of which $54.5 \%$ were females and $46 \%$ were males, representing a sample fraction of $2.23 \%$ out of 360,000 students enrolled in the public and private schools of São Paulo. In regard to student distribution in the fifth, sixth, seventh and eighth grades, 1,167, 1,039, 1,141 , and 1,025 were females and 985, 921, 917 and 825 were males, respectively. No significant gender difference was seen between school grades. Age distribution of female and male students was as follows: 180 and 134 aged 10 years old; 891 and 765 aged $11 ; 999$ and 814 aged $12 ; 104$ and 904 aged 13; 962 and 787 aged 14; and 234 and 242 aged 15, respectively, with random 
age difference. Data were collected between September 2004 and June 2005 and the sample included $74.8 \%$ of public and $25.2 \%$ of private school students.

\section{Anthropometric measurements}

The study variables were evaluated by a team consisting of 20 female interns (Nutrition and Physical Education students) and four 4 female coordinators (Master's students, two of them authors of the present article) who were previously trained on taking anthropometric measurements. To assure the evaluation's quality a pilot study was carried out after training to assess reliability and objectivity of the evaluators' measures taken. This pilot study was key not only to reduce variability between evaluators but also to minimize interference in the school routine given the large number of students evaluated. The whole project was coordinated by a child/adolescent Physician and a Nutritionist, both teachers at a Federal University.

Adolescents were weighed wearing light clothing and no shoes on a portable digital scale $\left(\right.$ Tanita $^{\circledR}$ ) with $150 \mathrm{~kg}$ capacity. Their height was determined by means of a wall-mounted digital stadiometer $\left(\mathrm{Seca}^{\circledR}\right)$. These measures were taken based on the criteria as described by Jellife (8). BMI was calculated by dividing weight in kilograms $(\mathrm{kg})$ by height in square meters $\left(\mathrm{m}^{2}\right)$ as established by the US Centers for Disease Control and Prevention (CDC) (9). Low weight was defined when BMI values were below the $5^{\text {th }}$ percentile $(<\mathrm{P} 5)$; normal weight when BMI values were at or above the $5^{\text {th }}$ and below the $85^{\text {th }}$ percentiles (P5-P85); overweight when they were at or above the $85^{\text {th }}$ and below the $95^{\text {th }}$ percentile (P85-P95); and obese when they were at or above the $95^{\text {th }}$ percentile ( $\left.\geq \mathrm{P} 95\right)$.

The study protocol was approved by the Graduate Research Board, and Research Ethics Committee of the Federal University of São Paulo. Only those adolescents whose parents or legal guardians had given their written consent participated in the study.

\section{Data analysis}

In order to describe the profile of the sample according to the variables studied, frequency tables for categorical variables (gender, age group) were created and descriptive statistics (mean, standard deviation, minimum and maximum values) for continuous variables (age, height, weight and BMI) were calculated. Student's t-test was used to assess the difference of the numerical variables of interest by gender and the analysis of variance (oneway ANOVA) was performed to assess differences by age, followed by the Tukey's post-hoc multiple comparison test. For asymmetric variables or those without a normal distribution the logarithmic transformation $(\log 10)$ was performed before calculating the statistical test. The level of significance adopted for all the statistical tests was $5 \%$, that is, $\mathrm{p}<0.05(10-13)$.

Data were pre-arranged for the analysis of distribution of BMI values in the sample studied, from the lowest (minimum) to the highest (maximum), and then subdivided into 100 parts of equivalent sizes (percentiles). The values corresponding to $\mathrm{P} 5, \mathrm{P} 10, \mathrm{P} 15, \mathrm{P} 25, \mathrm{P} 50, \mathrm{P} 75$, P85, P90 and P95 by gender and age, were adopted.

The chi-square test was used to compare BMI percentiles by gender. Based on these BMI percentiles, we developed the respective curves by age and gender and compared the BMI cut-offs of the sample studied to the parameters established by Cole and cols. (14), Must and cols. (15) and CDC (9) as they are international references largely used in Brazil.

Statistical analyses were conducted using SAS (Statistical Analysis System) for Windows, version 6.12 (SAS Institute Inc, 1989-1996, Cary, NC, USA).

\section{RESULTS}

Table 1 shows the sample's descriptive statistics. When measures were corrected by logarithmic transformation, male adolescents had higher weight $(\mathrm{p}=0.036)$ and height $(\mathrm{p}<0.001)$ and lower BMI values $(\mathrm{p}=$ $0.004)$ than females but there were no statistically significant differences by age $(\mathrm{p}=0.36)$. Male adolescents had lower mean BMI and showed greater data variability (weight and height) as well.

Mean BMI values were higher among female than male adolescents in P10 (16.30 x 16.08; p = 0.006), P15 (16.90 x 16.57; p < 0.001), P25 (17.71 x 17.39; $\mathrm{p}<0.001)$, and P50 (19.72 x 19.31; p < 0.001, respectively). No statistically significant differences were seen in the remaining percentiles.

Table 2 shows BMI values in the percentiles by age and gender. Figure 1 and figure 2 present BMI curves for the sample studied in percentiles, by age and gender, in comparison to the parameters described by Must and cols. (15), CDC (9) and Cole and cols. (14). Cole and cols. (14) data are presented only for the $85^{\text {th }}$ and $95^{\text {th }}$ percentiles, corresponding to overweight and obesity, respectively. 
Table 1. Mean, standard deviation, minimum and maximum values by age and anthropometric measures of adolescents from São Paulo

\begin{tabular}{lccc}
\hline \multirow{2}{*}{ Variables } & \multicolumn{3}{c}{ Population } \\
\cline { 2 - 4 } & General & Female & Male \\
& $8020(100 \%)$ & $4372(54.5 \%)$ & $3648(45.5 \%)$ \\
\hline AGE (years) & & & \\
Mean (SD) & $13.04(1.27)$ & $13.03(1.26)$ & $13.06(1.29)$ \\
Minimum - Maximum & $10.00-14.92$ & $10.00-14.92$ & $10.00-14.92$ \\
WEIGHT (kg) & & & \\
Mean (SD) & $49.97(12.14)$ & $49.48(10.91)$ & $50.55(13.44)$ \\
Minimum - Maximum & $22.00-110.6$ & $24.80-106.20$ & $22.00-110.60$ \\
HEIGHT (cm) & & & \\
Mean (SD) & $156.67(9.68)$ & $155.77(7.87)$ & $157.75(11.39)$ \\
Minimum - Maximum & $124.50-189.30$ & $124.5-186.80$ & $125.83-189.30$ \\
BMI (kg/m²) & & & \\
Mean (SD) & $20.17(3.69)$ & $20.26(3.59)$ & $20.07(3.80)$ \\
Minimum - Maximum & $10.74-54.80$ & $10.74-40.29$ & $11.75-54.80$ \\
\hline
\end{tabular}

\section{DISCUSSION}

Studies on the indicators of overweight and obesity in childhood and adolescence have brought about many investigations on the prognosis of health risk (16-25).

Some authors have shown preference for the definition of cut-offs based on statistical criteria of mortality or those that point to continuing overweight and obesity in childhood, adolescence and adulthood (26-27).

Cole and cols. (14) study was one of the first to present BMI values in agreement with this trend. There are other publications with borderline BMI values that are also used to identify children with overweight and obesity (28-30).

Many authors consider it not possible to either estimate worldwide prevalence of obesity in children or compare prevalences due to the diversity of criteria used (31-32). National studies on indicators of nutritional state in adolescence are still too limited and usually restricted to developed countries and the real magnitude of this condition is not known in developing societies (33). Considering the multiracial character of the Brazilian population, and specifically of adolescents of our study, we found how important it is for researchers to establish BMI values based on the population they intend to study so that an early diagnosis of overweight can be made.

Excess weight was seen in $23 \%$ of public and $33 \%$ of private school adolescents. Of them, $8.21 \%$ and $7.83 \%$ of girls, and $9.91 \%$ and $17.84 \%$ of boys were obese, respectively.

As the most widely used scales in health are those with scores expressed in percentiles, we decided to use them to assess the distribution of BMI in adolescents aged between 10 and 15 years from the city of São Paulo. Percentiles indicate the relative position of an individual within a group, showing the position of those who are above or below a given score. The advantage of using percentile tables is that their values are not affected by the distribution of raw scores, and they do not take into consideration the mean and data variability (34).

BMI distribution in percentiles shows different values from those reported in other national studies, especially those at the upper limits of distribution, which are related to body fat. Anjos and cols. (35), based on data from the Brazilian National Survey on Health and Nutrition (PNSN, Brazil), found that mean BMI values in the $85^{\text {th }}$ and $95^{\text {th }}$ percentiles for female adolescents

Table 2. Body mass index (BMI) percentiles by age and gender for the study adolescents

\begin{tabular}{|c|c|c|c|c|c|c|c|c|c|c|c|}
\hline Gender & Age & $\mathbf{n}$ & P5 & P10 & P15 & P25 & P50 & P75 & P85 & P90 & P95 \\
\hline \multirow[t]{6}{*}{ Female } & 10 & 180 & 14.69 & 15.29 & 15.61 & 16.42 & 18.18 & 20.80 & 22.17 & 23.44 & 25.41 \\
\hline & 11 & 891 & 15.09 & 15.70 & 15.99 & 16.78 & 18.69 & 21.15 & 22.66 & 24.16 & 25.84 \\
\hline & 12 & 997 & 15.16 & 16.00 & 16.43 & 17.27 & 19.22 & 21.56 & 23.39 & 24.67 & 26.89 \\
\hline & 13 & 1106 & 16.28 & 16.98 & 17.34 & 18.15 & 20.00 & 22.24 & 23.95 & 25.32 & 27.49 \\
\hline & 14 & 961 & 16.61 & 17.34 & 17.89 & 18.83 & 20.81 & 22.95 & 24.59 & 25.73 & 27.63 \\
\hline & 15 & 234 & 17.40 & 18.02 & 18.53 & 10.31 & 20.65 & 22.50 & 24.11 & 25.31 & 27.79 \\
\hline \multirow[t]{6}{*}{ Male } & 10 & 134 & 15.16 & 15.66 & 15.92 & 16.48 & 17.77 & 20.63 & 22.55 & 23.67 & 25.93 \\
\hline & 11 & 765 & 15.22 & 15.63 & 16.01 & 16.70 & 18.49 & 21.45 & 23.24 & 24.53 & 26.15 \\
\hline & 12 & 816 & 15.06 & 15.73 & 16.18 & 16.88 & 18.71 & 21.64 & 23.64 & 24.91 & 27.02 \\
\hline & 13 & 902 & 15.55 & 16.40 & 16.89 & 17.70 & 19.50 & 22.31 & 24.26 & 26.04 & 28.30 \\
\hline & 14 & 786 & 16.44 & 17.02 & 17.57 & 18.27 & 19.71 & 22.22 & 23.86 & 25.76 & 27.70 \\
\hline & 15 & 242 & 16.61 & 17.24 & 17.67 & 18.65 & 20.36 & 22.47 & 24.00 & 25.62 & 29.84 \\
\hline
\end{tabular}


Mean BMI percentiles - Females aged 10

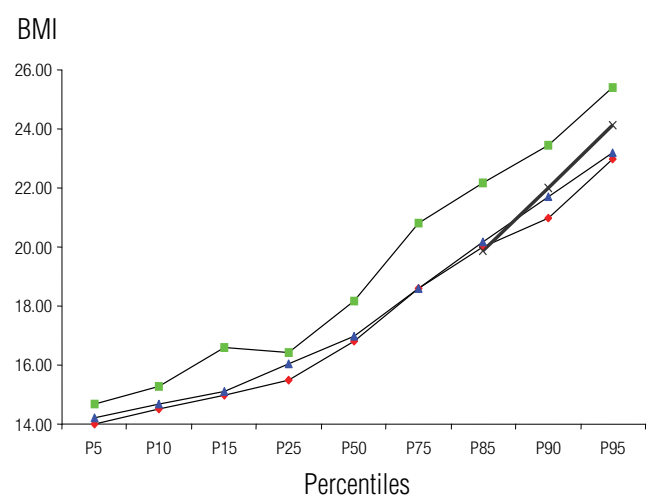

Mean BMI percentiles - Females aged 12

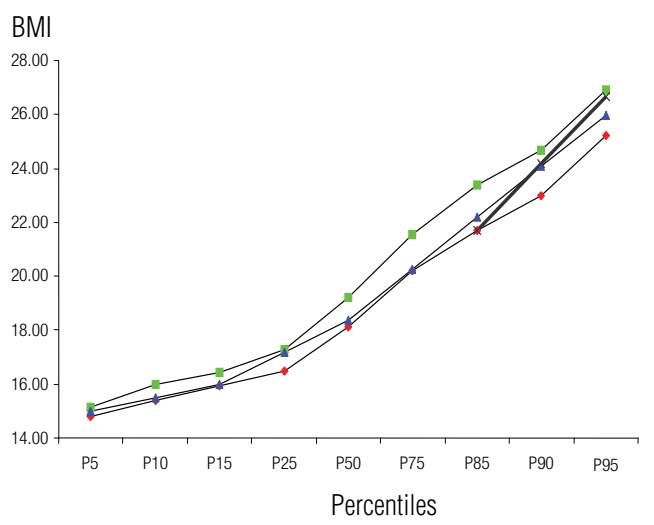

Mean BMI percentiles - Females aged 14

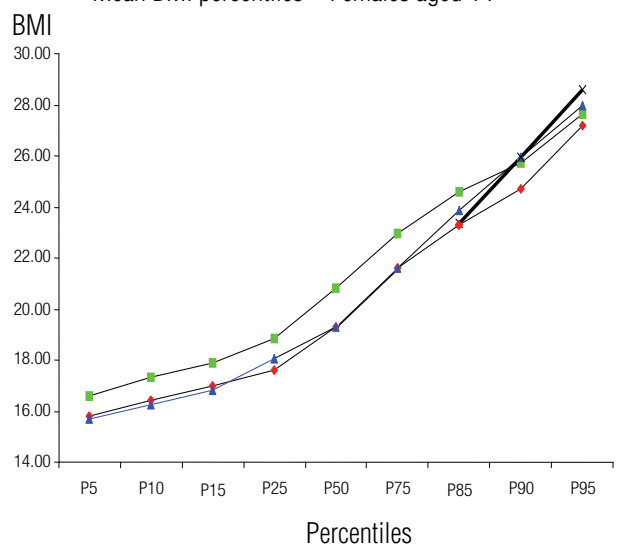

Mean BMI percentiles - Females aged 11
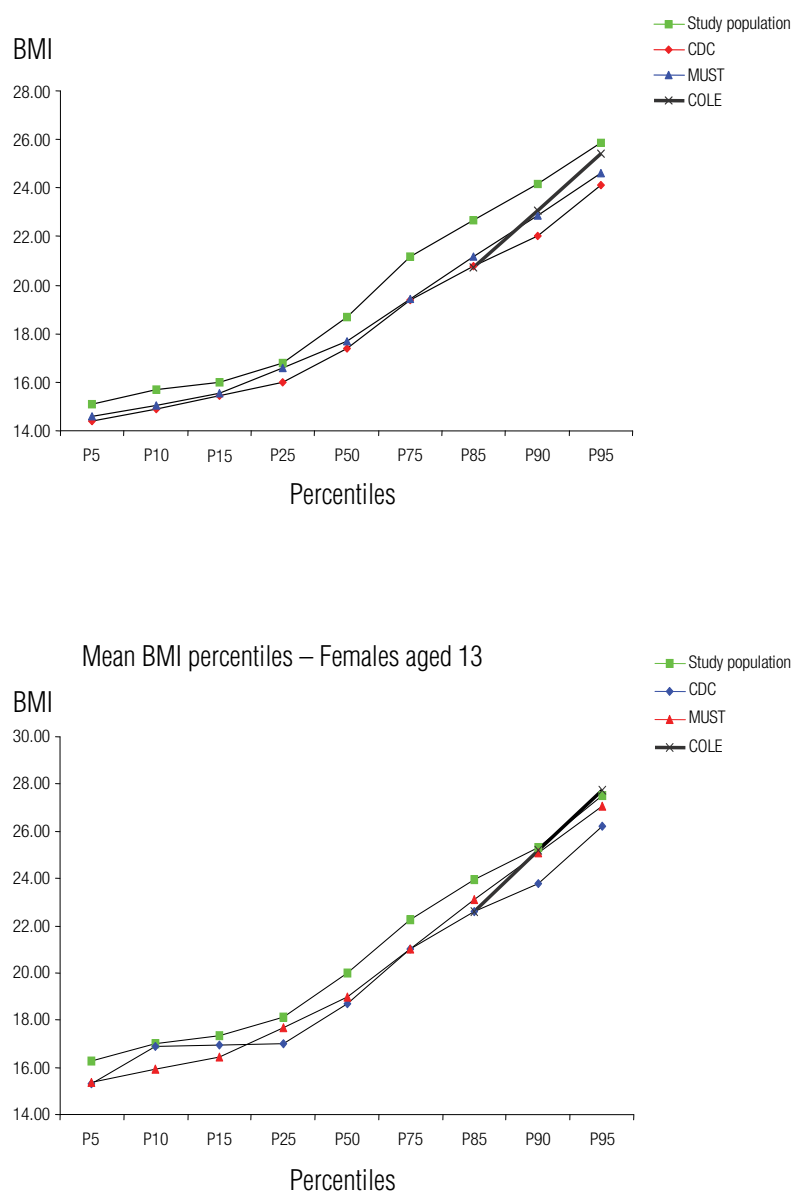

Mean BMI percentiles - Female aged 15

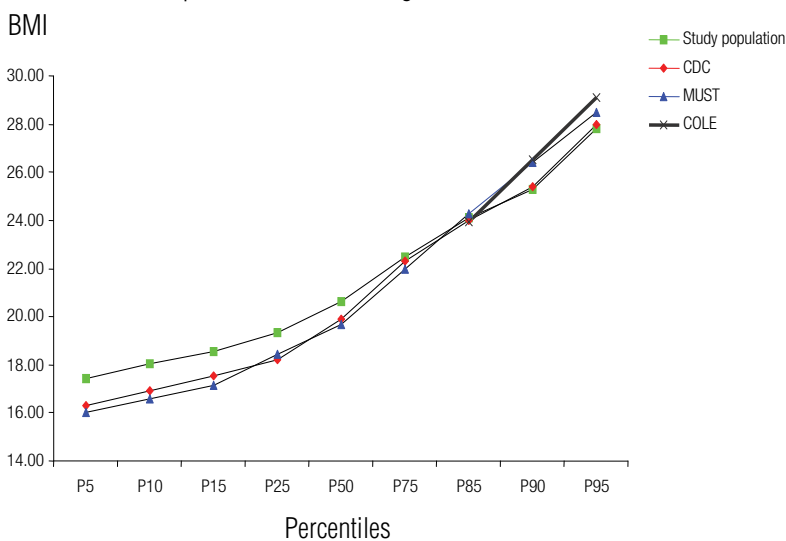

Figure 1. Comparison of BMI percentiles to international parameters in female adolescents by age.

aged between 10 and 15 years were 21.01 and $23.23 \mathrm{~kg} / \mathrm{m}^{2}$, respectively, while for male adolescents they were 19.73 and $21.9 \mathrm{~kg} / \mathrm{m}^{2}$, respectively. In the present study, mean BMI values in the $85^{\text {th }}$ and $95^{\text {th }}$ percentiles for female adolescents of the same age group were 23.47 and $26.84 \mathrm{~kg} / \mathrm{m}^{2}$ compared to 24.90 and $27.49 \mathrm{~kg} / \mathrm{m}^{2}$, respectively, for male adolescents.

When we compared Anjos and cols. (35) data to the results of the present study, we found a mean BMI increase (lower limit - upper limit) of $2.46(0.51-4.06)$ 


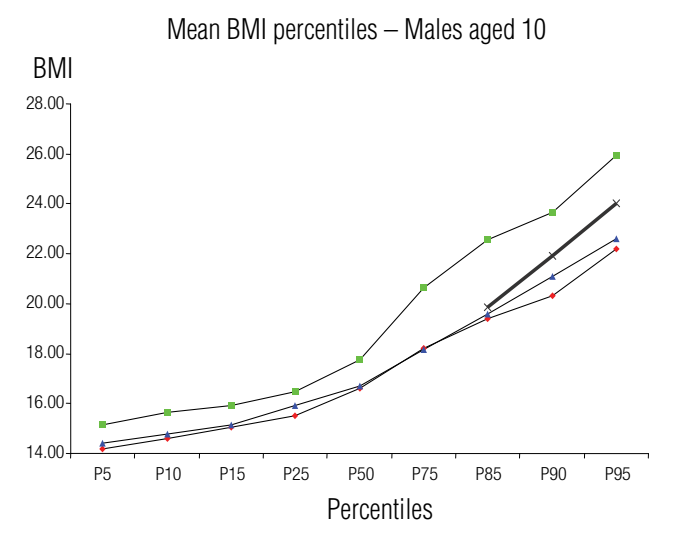

Mean BMI percentiles - Males aged 12

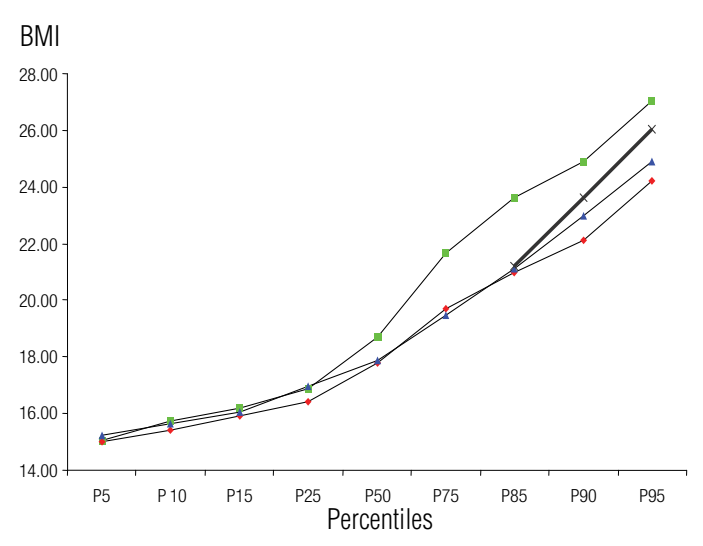

Mean BMI percentiles - Males aged 14

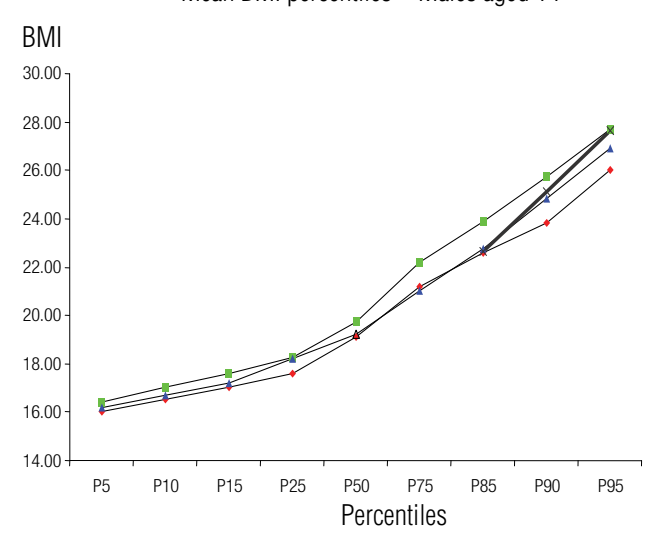

Mean BMI percentiles - Males aged 11

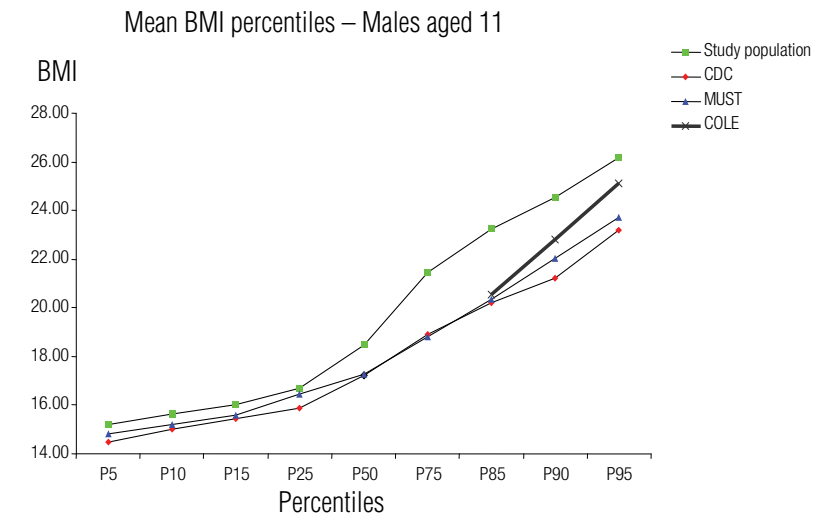

Mean BMI percentiles - Males aged 13
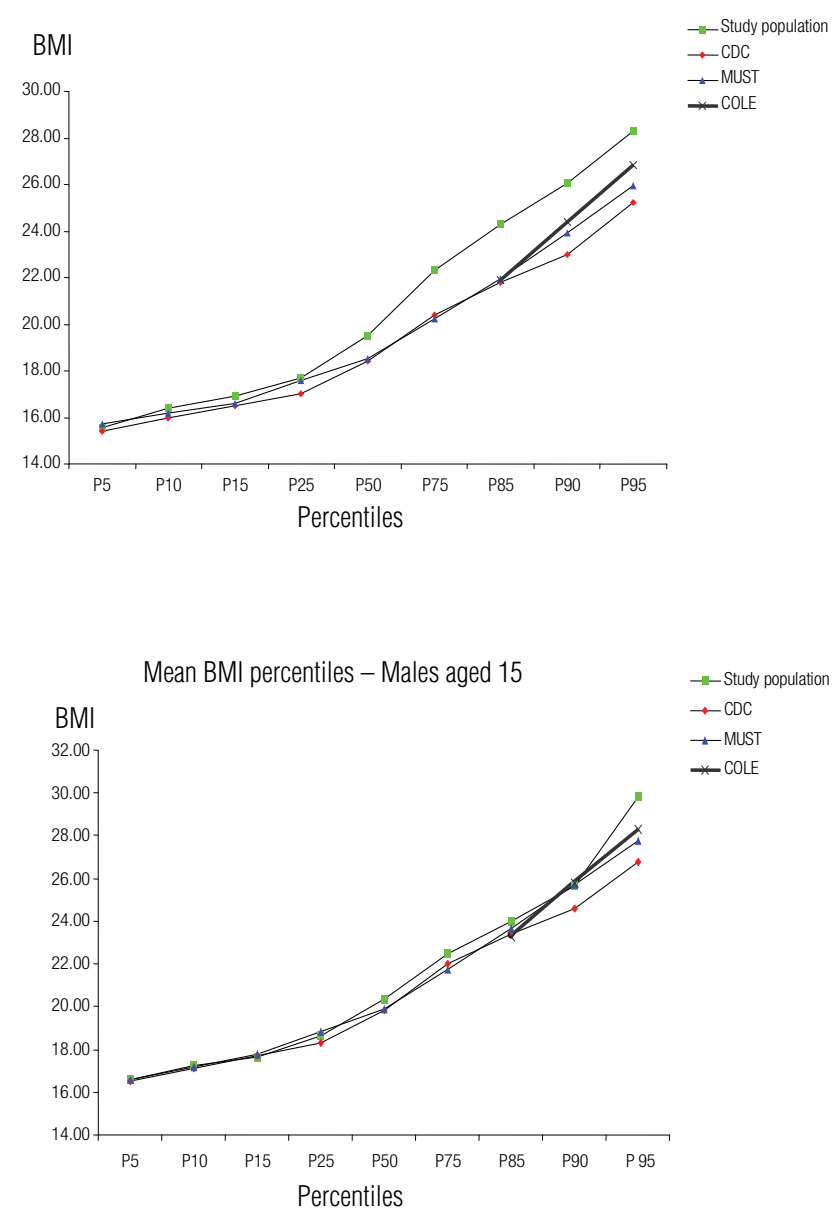

Figure 2. Comparison of BMl percentiles to international parameters in male adolescents by age.

units in P85 and $3.61(1.63-5.81)$ units in P95 for female adolescents. As for male adolescents, the mean BMI increase was $5.17(3.92-5.94)$ units in P85 and 5.6 (4.85 - 6.4) units in P95.

These results show that both female and male adolescents between 10 and 15 years of age, but especially males, have higher BMI values and, therefore, more body fat compared to previous studies, such as the Anjos and cols. (35) study in which data were collected over 15 years ago.

McCarthy and cols. (36), by comparing data from the National Diet and Nutrition Survey (1997) and 
data from the British Standards Institute (males, 1977; female, 1987) of British adolescents aged 11 to 16, reported, by means of the standard deviation score, a mean increase of 0.47 and 0.53 units in BMI of males and females, respectively. Although in the present study we did not evaluate BMI values in scores, we noted an inversion of the higher increases in relation to the female. This inversion was not influenced by weight changes that take place for a period, a fact known to have great impact on the increase of obesity prevalence as well as on its severity.

The prevalence of overweight and obesity in Brazil is increasing following the trend seen worldwide (37$40)$. The values found for BMI percentiles in both female and male adolescents aged 10 to 15 (Figures 1 and 2) were higher than those proposed by Must and cols. (15), CDC (9), and Cole and cols. (14). The main differences were seen in the upper limits (P85 and P95) for 10- and 11-year-old females and 10- to 13-year-old males.

In regard to the girls studied, BMI values found for the $85^{\text {th }}$ percentile were higher to those reported in other studies for the ages of 10, 11, 12, 13 and 14, and similar for the age of 15 . As for the $95^{\text {th }}$ percentile, the values found were higher for the ages of 10 to 12 ; similar to those proposed by Cole and cols. (14) for the age of 13; and lower to those proposed by Cole and cols. (14) and Must and cols. (15) for the ages of 14 and 15. The values found in the $85^{\text {th }}$ and $95^{\text {th }}$ percentiles for males aged 10 to 13 were much higher than those reported in other studies. The value in P95 for 14-year-old males was similar to that published by Cole and cols. (14). In regard to 15 -year males, the value in the $95^{\text {th }}$ percentile was much higher than that described in other studies.

It seems that the cut-offs for overweight and obesity proposed by Cole and cols. (14) were the ones with the closest similarity to those in the sample studied.

Considering that the Brazilian population is miscegenated, it would be interesting for future studies to focus on differences regarding ethnical aspects of growth and body composition since the groups have different characteristics, culture and habits.

The results of the present study describe different BMI percentiles in a representative sample of adolescents. It thus shows the importance for researchers to use these values while studying this population since, as corroborated by our results, international standards may not reflect the real condition of Brazilian adolescents aged between 10 and 15 .
Disclosure: Mauro Fisberg received aid for research for the following companies: Abbott, Danone, Kraft, ABIR, ABITRIGO and Nestlé. The remaining authors declare they have no conflict of interest.

\section{REFERENCES}

1. Bini V, Celi F, Berioli MG, Bacosi ML, Stella P, Giglio P, et al. Body mass index in children and adolescents according to age and pubertal stage. Eur J Clin Nutr. 2000;54(3):214-18.

2. Pietrobelli A, Faith MS, Allison DB, Gallagher D, Chiumello G, Heymsfield SB. Body mass index as a measure of adiposity among children and adolescents: a validation Study. J Pediatr. 1998;132(2):204-10.

3. Mei Z, Grummer SLM, Pietrobelli A, Goulding A, Goran MI, Dietz WH. Validity of body mass index compared with other body-composition screening indexes for the assessment of body fatness in children and adolescents. Am J Clin Nutr. 2002;75(6):978-85.

4. WHO Expert Committee on Hypertension Control. Cardiovascular Diseases. Geneva; 1994/2001.

5. Belizzi MC, Dietz WH. Workshop on childhood obesity: summary of the discussion. Am J Clin Nutr. 1999;70(1):173S-5S.

6. Ebbeling CB, Pawlak DB, Ludwig DS. Childhood obesity: publichealth crisis, common sense cure. Lancet. 2002;360(9331):473-82.

7. Wang $Y$, Wang JO. A comparison of international references for the assessment of child and adolescent overweight and obesity in different populations. Eur J Clin Nutr. 2002;56(10):973-82.

8. Jelliffe DB. The assessment of the nutritional status of the community. WHO monograph, 53. Geneva: 1966.

9. CDC - Center for disease control and prevention. 2000 CDC Growth charts: United States [online] Hyaltsville: 2002. Accessed on: Jan 15 2003. Available from: www.cdc.gov/growthcharts.

10. Conover WJ. Practical nonparametric statistics. New York: John Wiley \& Sons; 1971.

11. Siegel S. Estatística não-paramétrica para as ciências do comportamento. São Paulo: MC Graw-Hill; 1975.

12. Miliken GA, Johnson DE. vol. 1. Analysis of messy data. Designed Experiments. NewYork: Van Nostrand Reinhold Company; 1984.

13. Montgomery DC. Design and analysis of experiments. 3th ed. New York: John Wiley Sons; 1991.

14. ColeTJ, Bellizzi MC, Flegal KM, Dietz WH. Establishing a standard definition for child overweight and obesity worldwide: International Survey. BMJ. 2000;320:1240-3.

15. Must A, Dallal GE, Dietz WH. Reference data for obesity: 85th and 95th percentiles of body mass index (WT/Th2) and triceps skinfold thickness. Am J Clin Nutr. 1991;53(4):839-46.

16. Baker JL, Olsen LW, Sørensen TIA. Childhood body mass index and the risk of coronary heart disease in adulthood. $N$ Engl $J$ Med. 2007;357:2329-37.

17. Thompson DR, Obarzanek E, Franko DL, Barton BA, Morison J, Biro FM, et al. Childhood overweight and cardiovascular disease risk factors: The National Heart, Lung, and Blood Institute Growth and Health Study. J Pediatr. 2007;150(1):18-25.

18. Rosa ML, Mesquita ET, Rocha ER, Fonseca VM. Body mass index and waist circumference as markers of arterial hipertension in adolescents. Arq Bras Cardiol. 2007;88(5):573-8.

19. Morrison JA, Friedman LA, GrayMcGuire C. Metaboblic syndrome in childhood predicts adult cardiovascular disease 25 years later: the princeton lipid research clinics follow-up study. Pediatrics. 2007;120(2):340-5.

20. Mohan V, Deepa M, Farooq S, Narayan KMV, Datta M, Deepa R. Anthropometric cut points for identification of cardiometabolic risk factors in an urban Asian Indian population. Metabolism. 2007; $56: 961-68$. 
21. Morrison JA, Friedman LA, Wang $P$, Glueck CJ. Metabolic syndrome in childhood predicts adult metabolic syndrome and type 2 diabetes mellitus 25 to 30 years later. J Pediatr. 2008;152:201-6.

22. Bray GA, Jablonski KA, Fujimoto WY, Cannor EB, Haffner S, Hanson $\mathrm{RL}$, et al. Relation of central adiposity and body mass index to the development of diabetes in the Diabetes Prevention Program. Am J Clin Nutr. 2008;87(5):1212-8.

23. Denney WE, Hardy LL, Dobbins T, Okely AD, Baur LA. Body mass index, waist circumference and chronic disease risk factors in Australian adolescents. Arch Pediatr Adolesc Med. 2008;162(6):566-73.

24. Santos LC, Cintra IP, Fisberg M, Martini LA. Body trunk fat and insulin resistance in post pubertal obese adolescents. Med J. 2008;126(2):82-6.

25. Messiah SE, Arheart KL, Lpshultz SE, MillerTL. Body Mass Index, waist circumference, and cardiovascular risk factors in adolescents. J Pediatr. 2008;153(6):845-50.

26. Lawlor DA, Hart CL, Hole DJ, Davey SG. Reverse causality and confounding and the associations of overweight and obesity with mortality. Obesity. 2006;14:2294-304.

27. Gelber RP, Kurth T, Manson JE, Buring JE, Gaziano JM. Body mass index and mortality in men: evaluating the shape of the association. Int J Obes. 2007;31(8):1240-7.

28. ColeTJ, Roede MJ. Centiles of body mass index for dutch children aged 0-20 years in 1980 - a baseline to assess recent trends in obesity. Ann Hum Biol. 1999;26(4):303-8.

29. Luciano A, Bressan F, Zoppi G. Body mass index reference curves for children aged 3-19 years from Verona, Italy. Eur J Clin Nutr. 1997;51:6-10.

30. Turconi G, Guarcello M, Maccarini L, Bazzano R, Zaccardo A, Roggi C. BMI values and other anthropometric and functional mea- surements as predictors of obesity in a selected group of adolescents. Eur J Nutr. 2006;45:136-43.

31. Guillaume M. Defining obesity in childhood: Current practice. Am J Clin Nutr. 1999;70:126S-30S.

32. Livingstone MB. Childhood obesity in Europe: a growing concern. Public Health Nutr. 2001;4:109-16.

33. World Health Organization. Obesity: preventing and managing the global epidemic. Report of WHO Consultation on obesity. Geneva:WHO; 1998.

34. Baumgartner RN, Heymsfield SB, Roche AF. Human body composition and the epidemiology of chronic disease. Obes Rev. 1995;3(1):73-95.

35. Anjos LA, Veiga GV, Castro IRR. Distribuição dos valores do índice de massa corporal da população brasileira até 25 anos. Rev Panam Salud Publica [online]. 1998;3(3):164-73.

36. McCarthy HD, Ellis SM, Cole TJ. Central Overweight and obesity in Bristish youth aged 11-16 years: Cross sectional surveys of waist circumference. BMJ. 2003;326:624-27.

37. Costa RF, Cintra IP, Fisberg M. Prevalência de sobrepeso e obesidade em escolares da Cidade de Santos, SP. Arq Bras Endocrinol Metab. 2006;50(1):60-7.

38. Cintra IP, Passos MAZ, Fisberg M, Machado HC. Evolution of body mass index in two historical series of adolescents. J Pediatr (Rio J). 2007;83(2):157-62.

39. Ferreira A, Oliveira CER, França NM. Síndrome metabólica em crianças obesas e fatores de risco para doenças cardiovasculares de acordo com a resistência à insulina. J Pediatr (RJ). 2007;83(1):21-6.

40. Wang Y, Monteiro C, Popkin BM. Trends of obesity and underweight in older children and adolescents in the United States, Brasil, China and Rusia. Am J Clin Nutr. 2002;75(6):971-7. 